\title{
Bacterial community structure in rotating biological contactor treating coke wastewater in relation to medium composition
}

\author{
Aleksandra Ziembińska-Buczyńska ${ }^{1} \cdot$ Sławomir Ciesielski ${ }^{2} \cdot$ Sebastian Żabczyński ${ }^{1}$ • Grzegorz Cema ${ }^{1}$
}

Received: 10 July 2018 / Accepted: 4 April 2019 / Published online: 3 May 2019

(C) The Author(s) 2019

\begin{abstract}
Biological wastewater treatment using biofilm systems is an effective way to treat difficult wastewater, such as coke wastewater. The information about the structure and the dynamics of this microbial community in biofilm, which are responsible for wastewater treatment, is relevant in the context of treatment efficacy and the biochemical potential to remove various pollutants. However, physico-chemical factors can influence the biofilm community significantly, causing performance disturbances. Therefore, we decided to examine the structure of microbial community in rotating biological contactor (RBC) biofilm during coke wastewater treatment and to investigate the possible shift in the community structure caused by the feeding medium change from synthetic to real coke wastewater. The experiment performed with high-throughput next-generation sequencing (NGS) revealed that bacteria commonly present in wastewater treatment plant (WWTP) systems, responsible for nitrite oxidizing, such as Nitrospira or Nitrobacter, were absent or below detection threshold, while Nitrosomonas, responsible for ammonia oxidizing, was detected in a relatively small number especially after shift to real coke wastewater. This research indicates that medium change could cause the change from autotrophic into heterotrophic nitrification led by Acinetobacter. Moreover, biofilm systems can be also a potential source of bacteria possessing high biochemical potential for pollutants removal but less known in WWTP systems, as well as potentially pathogenic microorganisms.
\end{abstract}

Keyword NGS $\cdot$ Coke wastewater $\cdot$ Biofilm $\cdot$ Bacterial community shift

\section{Introduction}

Biological wastewater treatment is a universal and effective method for purification of the majority of liquid wastes. However, some industrial wastewaters, such as coke wastewater, are difficult to be treated with these methods. For coke wastewater, the presence of recalcitrants such as phenols, cyanides, thiocyanides, or heavy metals can interrupt the treatment

Responsible editor: Gerald Thouand

Electronic supplementary material The online version of this article (https://doi.org/10.1007/s11356-019-05087-0) contains supplementary material, which is available to authorized users.

Aleksandra Ziembińska-Buczyńska

Aleksandra.ziembinska-buczynska@polsl.pl

1 Environmental Biotechnology Department, Silesian University of Technology, Akademicka 2, 44-100 Gliwice, Poland

2 Faculty of Environmental Sciences, Department of Environmental Biotechnology, University of Warmia and Mazury in Olsztyn, Słoneczna 45G, 10-719 Olsztyn, Poland procedure performed with activated sludge (Pal and Kumar 2014). The microbial cooperation of nitrogen removal bacteria with the other groups of microorganisms present in the wastewater treatment plant (WWTP) community results in efficient wastewater treatment. Such microbial interactions are modeled by physico-chemical parameters influencing the technological systems especially in biological wastewater treatment. The structure and the dynamics of this microbial community can be influenced by external factors such as $\mathrm{pH}$, temperature, substrate, and oxygen concentration (Cydzik-Kwiatkowska and Zielińska 2016). One of the factors influencing bacterial community during wastewater treatment is the wastewater composition (Cydzik- Kwiatkowska et al. 2012; Zhang et al. 2018). The feeding medium change (from municipal to industrial or from synthetic to real wastewater) can cause a drastic shift of the bacterial community structure and it can influence dramatically nitrogen and recalcitrant removal. The feeding medium shift, highly dangerous for activated sludge bacteria, can be led in biofilm-based systems with the relatively lower possibility of bacterial community damage because of the high amount of extrapolimeric substances (EPS) protective against harmful 
physico-chemical factors influencing the biocoenosis. Moreover, biofilm-based systems are recognized to be an excellent model for ecological relationships research among bacteria in the community due to their direct contact and relatively closer location to each other (Cydzik-Kwiatkowska et al. 2012; Zhang et al. 2018).

Technological systems based on biofilm, to which rotating biological contactors (RBCs) belong, are regarded as a promising technology for treating harmful wastewater. The advantages of such systems are higher biomass concentration, small size, and relatively high efficacy (Cortez et al. 2008; Duque et al. 2014). As such, it provides an excellent opportunity to study numerous bacterial groups present in biofilm communities (Ciesielski et al. 2010). Although there are studies showing the composition of microbial communities in the biofilm of $\mathrm{RBC}$, there is a lack of detailed information about microorganisms responsible for coke wastewater treatment and their community shift while feeding medium change.

Therefore, the main goal of this work was to examine the structure of microbial community in $\mathrm{RBC}$ biofilm during coke wastewater treatment and to investigate the possible shift caused by the feeding medium change from synthetic to real coke wastewater. Total bacterial community description was performed using high-throughput next-generation sequencing (NGS) method in order to present a total picture of the community shift.

\section{Materials and methods}

\section{Experiment settings and biofilm sampling}

The experiment was performed in the laboratory scale rotating biological contactor (Fig. 1). The RBC consisted of three chambers with 12 disks (a group of four per chamber). The disk diameter and total disk surface were equal to $0.225 \mathrm{~m}$ and
$2.61 \mathrm{~m}^{2}$, respectively. The immersion of disks was around $41 \%$ and the working volume of RBC was $0.014 \mathrm{~m}^{3}$. To prevent algal growth and maintaining a stable temperature, the RBC unit was covered by polystyrene foam. The temperature during the experiment was kept at an average level of $20.2 \pm 2.2{ }^{\circ} \mathrm{C}$. The $\mathrm{pH}$ in the inflow did not exceed 8.3 throughout the course of the experiment.

The experiment was operated for 823 days and divided into two periods. In the first experimental period, the RBC was fed with artificial coke wastewater for 719 days (days 0-719). The second experimental period involved treating the $\mathrm{RBC}$ with real coke wastewater from "Jadwiga" coke plant in Zabrze (Southern, Poland) for 104 days (days 719-823). A more detailed description of the experimental system, together with the composition of synthetic and real coke wastewaters used for the experiments, is described elsewhere (Cema et al. 2016).

Biofilm samples (volume of $20 \mathrm{~mL}$ ) were collected from all RBC disks, mixed together to create a composite sample, and frozen at $-45^{\circ} \mathrm{C}$ until further processing.

\section{DNA extraction}

Genomic DNA was extracted from $0.2 \mathrm{~g}$ of semi-dry biofilm samples collected at days 632 and 823 of the process. DNA was isolated using the FastDNA Spin Kit for soil (MP Biomedicals, USA) as per the instructions of the manufacturer. Qubit 2.0 Fluorometer (Invitrogen, USA) was used to obtain accurate DNA quantification. The purified DNA was suspended in $100 \mu \mathrm{L}$ of deionized, DNAase free water and stored at $-20^{\circ} \mathrm{C}$.

\section{Library preparation and Illumina sequencing}

The microbial community was analyzed by the amplification of the V3-V4 regions of the 16S rRNA gene, performed with

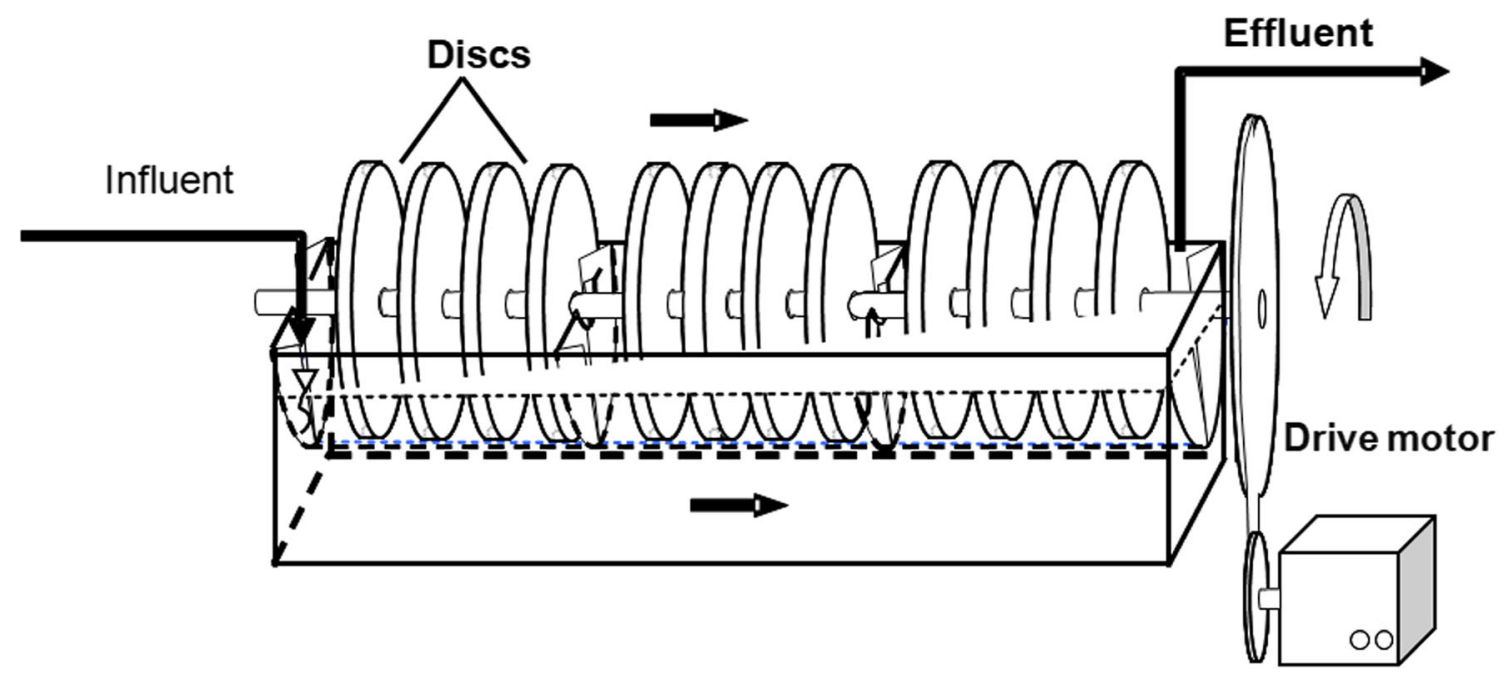

Fig. 1 The scheme of rotating biological contactor used in the study (Cema et al. 2016) 
S-D-Bact-0341-b-S-17 (5' TCGTCGGCAGCGTCAGATGT GTATAAGAGACAGCCTACGGGNGGCWGCAG 3') and S-D-Bact-0785-a-A-21 (5' GTCTCGTGGGCTCGGAGATG TGTATAAGAGACAGGACTACHVGGGTATCTAATC 3') Illumina-recommended primers (Klindworth et al. 2013). Amplicons were indexed using Nextera ${ }^{\circledR}$ XT Index Kit according to the manufacturer's instructions. DNA was sequenced on an Illumina MiSeq instrument using a $2 \times 250$ paired-end mode.

\section{Bioinformatics analyses}

The sequencing results were recorded as FASTQ files and uploaded to the MetaGenome Rapid Annotation Subsystems Technology (MG-RAST) server where normalization, transformation, and alpha diversity measurement were conducted (Meyer et al. 2008). Each file underwent quality control (QC), which included quality filtering (removing sequences with $\geq 5$ ambiguous base pairs) and length filtering (removing sequences with a length $\geq 2$ standard deviations from the mean). The $16 \mathrm{~S}$ rRNA datasets are available at MG-RAST under accession numbers 4,629,653.3 (632) and 4,629,653.3 (823). Taxonomic differences were analyzed using the Statistical Analysis of Metagenomic Profiles (STAMP v. 2.1.3) (Parks and Beiko 2010). Statistically significant differences between samples were identified by Fisher's exact test combined with the Newcombe-Wilson method for calculating confidence. A column chart comparing the relative abundances of each class was generated using Microsoft Excel.

\section{Results and discussion}

\section{Physico-chemical changes after real wastewater introduction}

From the point of wastewater treatment efficacy, nitrogen removal is a crucial process and the researches on the nitrogen removal communities treating various sewage types are commonly performed (Kowalchuk et al. 1997; Rotthauwe et al. 1997; Nicolaisen and Ramsing 2002; Wertz et al. 2008; Vanparys et al. 2007; Attard et al. 2010).

In the case of coke wastewater, the situation is more complex. This sewage is regarded as difficult for biological treatment; thus, the bacterial community able to treat this wastewater needs to be specialized, easily adapting and relatively diverse in the case of the necessity of recalcitrant removal. The $\mathrm{RBC}$ biofilm bacterial community in this experiment was performing stable nitrogen removal from the beginning of the experiment on synthetic coke wastewater for 719 days. After this period, the real coke wastewater was introduced to the system and the experiment was performed further as it has been described in detail by Cema et al. (2016). Figure 2 presents the nitrogen removal in RBC system during the shift of the feeding medium change.

From 520th day of research and during period I of research, the average nitrogen concentration in the influent was equal to $930.5 \pm 263.0 \mathrm{mg} / \mathrm{L}$. The removal efficiency in RBC was 71.1 $\pm 20.3 \%$ with very efficient and stable ammonium nitrogen removal equal to $97.8 \pm 6.5 \%$ (Table 1 ). Also, the phenol removal was very efficient at $99.7 \pm 0.2 \%$ with an influent concentration equal from 175.6 to $32.3 \mathrm{mg} / \mathrm{L}$. After the shift to the real coke wastewater, the sudden process breakdown was observed (Fig. 2). The nitrogen removal drops from over $80 \%$ at the end of the period I to almost 0 at the beginning of period II. Also, phenol concentration was fluctuating. The rebuild of the nitrogen removal took over 150 days (the results of nitrogen fluctuation in the reactor were described in detail in Cema et al. 2016).

\section{The microbial community shift after real wastewater introduction}

The aim of this study was to present the shift of the stable performing bacterial community after the medium change from synthetic to real coke wastewater. In order to analyze the qualitative changes of the microbial community structure, we compared the 16S rRNA gene amplicons data derived from two samples taken during process performance strictly before (632 days) and after the medium change on day 823 (the last sample collected in the system fed with real wastewater). Alpha diversity values for samples taken at days 632 and 823 were 29.48 and 21.23 , respectively. Rarefraction curves for each of the samples were almost asymptotic suggesting that the majority of taxonomic diversity was uncovered. Both alpha diversity and rarefraction curves were examined using MG-RAST (Supp. 1, Fig. 1). Bacteria constitute $98.6 \%$ of the total community in sample 632 and $98.8 \%$ in sample 823 . Such a result is obtained in most research performed on the bacterial communities in wastewater systems (Ma et al. 2015).

At class level, 36 bacterial classes were found in 632 sample, and 33 bacterial classes in sample 823 . The proportions of the 8 major classes are presented in Fig. 3. Reads affiliated to Alphaproteobacteria, Betaproteobacteria, and Gammaproteobacteria constituted the majority of the communities. STAMP comparison at the class level shows significant differences between analyzed samples ( $P=95 \%$, Fig. 4). Gammaproteobacteria, Actinobacteria, Planctomycetia, and Gemmatimonadetes were overrepresented significantly in sample 632, whereas Alphaproteobacteria, Betaproteobacteria, Flavobacteria, and Deinococci were overrepresented in sample 823 (Fig. 4). The predominance of Betaproteobacteria in sample 823, $29.74 \%$ vs. $14.08 \%$ in sample 632, may be explained with the removal of betaproteobacterial representatives from the system, due to a 


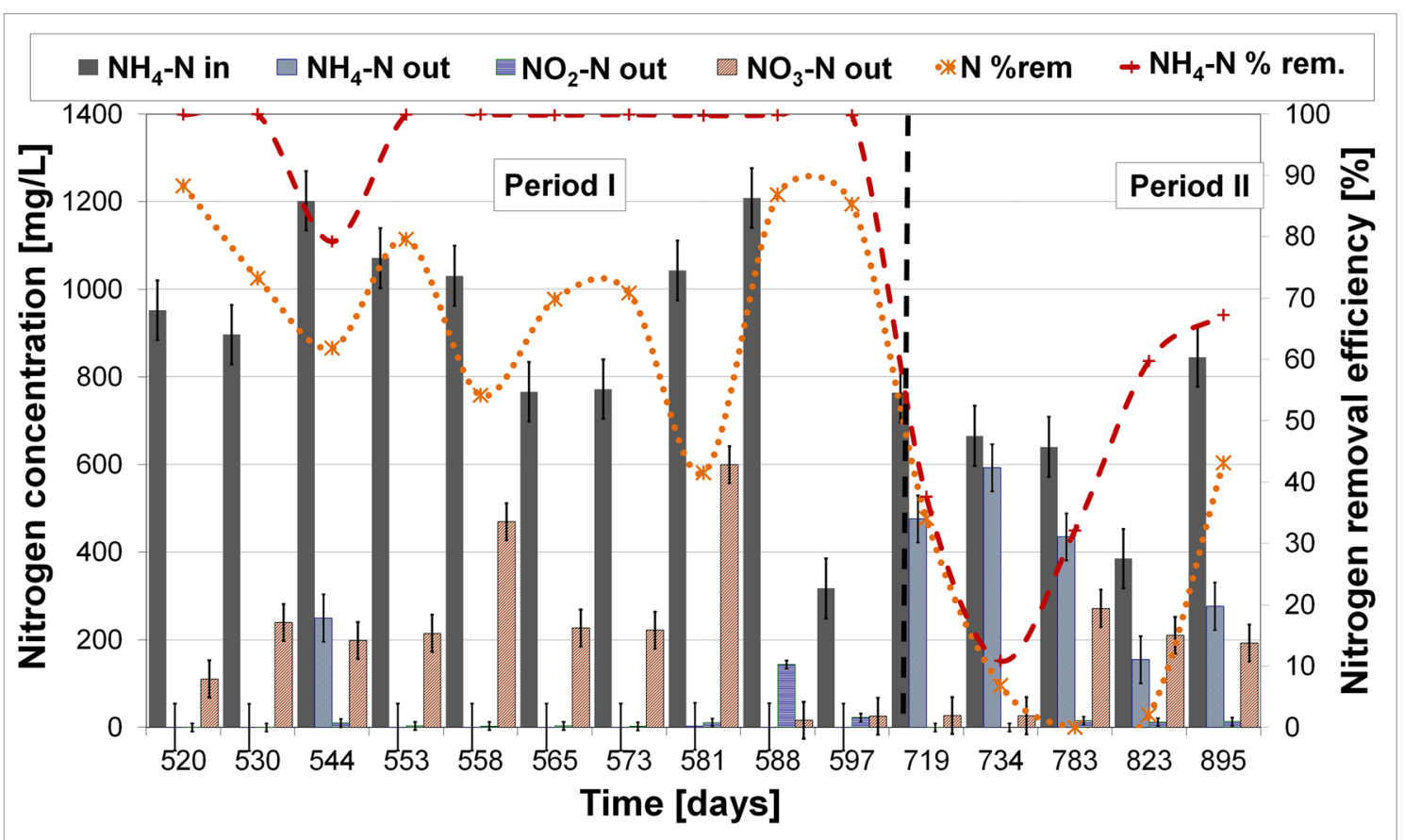

Fig. 2 Ammonia nitrogen removal performance in RBC during the total length of the experiment; period I - synthetic coke wastewater treatment; period II - real coke wastewater treatment (in - inflow, out - outflow, rem. - removal)

change in feeding medium, which in turn caused a decrease in nitrogen removal efficacy. In most cases, Betaproteobacteria are found to be predominant (Ma et al. 2015; Felföldi et al. 2010), but in WWTPs dealing with phenol-rich wastewater (such as coke wastewater), Alphaproteobacteria and Gammaproteobacteria were predominant (Figuerola and Erijman 2007; Wang et al. 2012) and Alphaproteobacteria can exceed Gammaproteobacteria (Xia et al. 2010). These results may also be attributed to the treatment method used. As it has been stated (Felföldi et al. 2010), Proteobacteria are predominant in most cases in WWTP systems, both in biofilm and activated sludge, but it is possible that the ratio of the particular Proteobacteria classes differs significantly when the analysis is performed with DNA sequencing or the other method (such as T-RFLP).

Research revealed the decrease of the Actinobacteria and Planctomycetia members during the process. Their abundance was reduced from 6.36 to $1.40 \%$ in the case of Actinobacteria and from 4.54 to $1.74 \%$ in the case of Planctomycetia. These results also underline the difference between wastewater systems based on activated sludge and biofilm. Moreover, these results could be linked with the decrease of nitrogen removal efficacy which in biofilm systems can be performed at large scale by Anammox process performed by Planctomycetia. In case the of activated sludge classes, Firmicutes, Chlorobi, and Chloroflexi are often dominant in the system (Felföldi et al. 2010; Ma et al. 2015; Wang et al. 2015), while for biofilm, these classes are not recognized as the main groups.

As it was previously stated by Cydzik-Kwiatkowska and Zielińska (2016) and Nascimento et al. (2018) also in the case of this research, the change of feeding wastewater can be the reason of the class proportion shift. It could be caused by the concentration changes in organic matter or recalcitrant substances.

Bacterial diversity and abundance were analyzed more specifically at the genus level (Tables 2 and 3). Table 2 showed genera which number increased during the process of coke wastewater treatment. The most significant change can be observed for Acinetobacter, Parabacteroides, Riemerella, and Pseudomonas. The number of these genera increased respectively: $567,77,36.17$, and 18.17 times, during the experiment time when the medium was changed from synthetic to

Table 1 Average values of nitrogen concentration, removal efficiency, and nitrogen load and removal rate during the shift of the feeding medium change (data presented with standard deviation)

\begin{tabular}{lllllll}
\hline & N in $(\mathrm{mg} / \mathrm{L})$ & $\mathrm{N}$ out $(\mathrm{mg} / \mathrm{L})$ & $\begin{array}{l}\text { N removal } \\
\text { efficacy }(\%)\end{array}$ & $\begin{array}{l}\mathrm{NH}_{4}-\mathrm{N} \text { removal } \\
\text { efficacy }(\%)\end{array}$ & $\begin{array}{l}\mathrm{N} \text { load } \\
\left(\mathrm{g} / \mathrm{m}^{2} / \mathrm{day}\right)\end{array}$ \\
\hline Synthetic wastewater & $930.5 \pm 263.0$ & $278.3 \pm 178.5$ & $71.1 \pm 20.3$ & $97.8 \pm 6.5$ & $1.4 \pm 0.5$ \\
Real wastewater & $660.4 \pm 174.7$ & $540.7 \pm 132.9$ & $17.2 \pm 19.9$ & $41.5 \pm 22.6$ & $0.7 \pm 0.4$ & $0.1 \pm 0.2$ \\
\hline
\end{tabular}




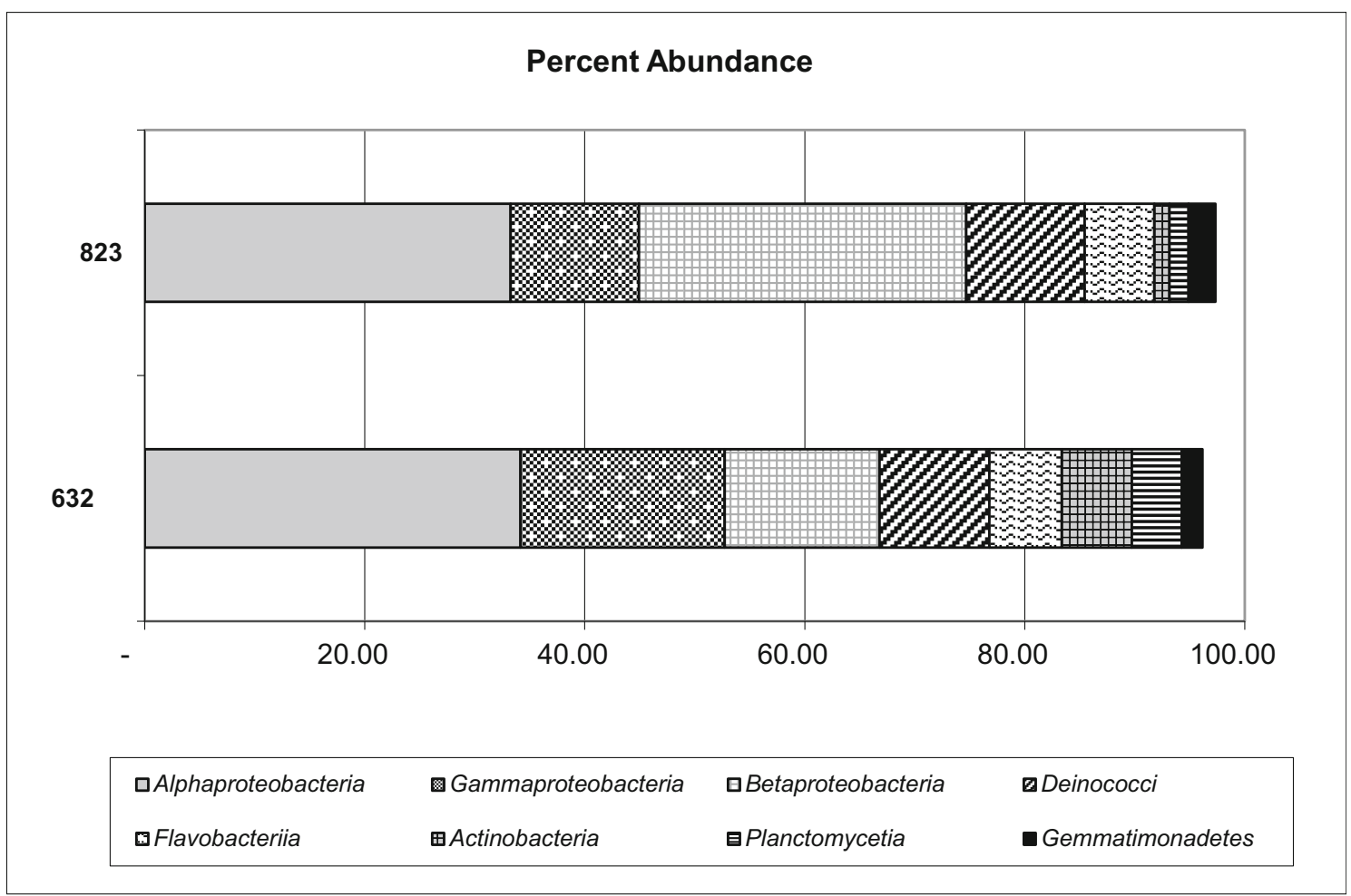

Fig. 3 Class level affiliations assigned to reads with $16 \mathrm{~S}$ rRNA genes in analyzed samples. Only classes with the relative abundance higher than $1.0 \%$ are given

real coke wastewater. These results support the previous research of Liu et al. (2015). They have isolated Acinetobacter from activated sludge treating coke wastewater which was able to remove ammonium, nitrite, and nitrate with a very high efficacy. Our results can support the thesis that real medium causes bacterial community change, seen especially in the group of nitrifiers, to prevent nitrogen removal breakdown. The activity of autotrophic nitrogen-removing bacteria in RBC (such as Nitrosomonas, Table 3) was suppressed by the harmful real coke wastewater directed to the system and such change created environment suitable for heterotrophic nitrogen-removing bacteria, such as Acinetobacter. Also, the increase of Pseudomonas bacteria number supports this thesis due to the fact that both Pseudomonas and Acinetobacter are common coke wastewater treatment plant inhabitants and they are also able to remove thiocyanates as a sole carbon source (Boucabeille et al. 1994; Huang et al. 2013). It is worth mentioning that heterotrophic nitrifiers have attracted increasing attention as this group of bacteria grow faster and is less sensitive towards high loads of ammonium and organic matter than autotrophic nitrifiers (Liu et al. 2015). It is known that heterotrophic nitrification could be performed under a wide range of $\mathrm{C} / \mathrm{N}$ ratio (Yang et al. 2017), but the research in this field are still scarce; thus, it would be reasonable to undertake

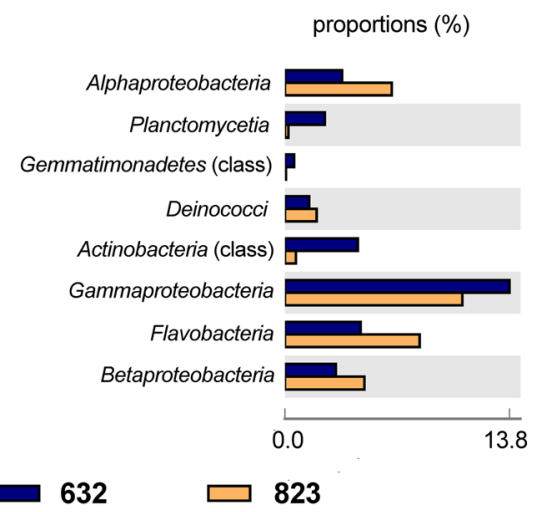

Fig. 4 Statistical analyses of taxonomic profiles for the 632 and 823 samples. Classes overrepresented in the 823 sample have a negative difference between proportions (orange dots); those overrepresented in
$95 \%$ confidence intervals

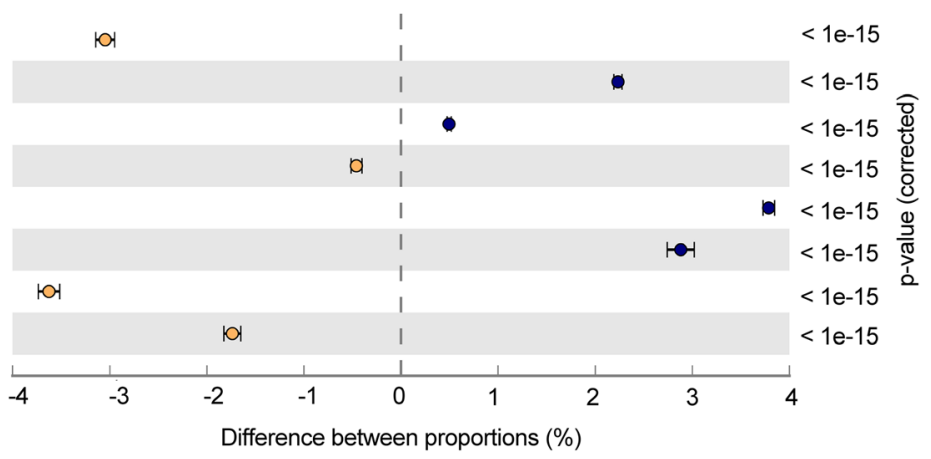

the 632 sample have a positive value difference between proportions (blue dots). Features with a $q$ value of 0.05 were considered significant 
Table 2 The list of bacterial genera that increased during process performance (only genera with the relative abundance higher than $0.1 \%$ are shown)

\begin{tabular}{llll}
\hline Genus & 632 sample & 823 sample & Change (fold) \\
\hline Acinetobacter & 0.01 & 5.67 & 567.00 \\
Parabacteroides & 0.02 & 1.54 & 77.00 \\
Riemerella & 0.06 & 2.17 & 36.17 \\
Pseudomonas & 0.06 & 1.09 & 18.17 \\
Bacteroides & 0.27 & 0.94 & 3.48 \\
Candidatus Solibacter & 0.23 & 0.57 & 2.48 \\
Bradyrhizobium & 0.56 & 1.32 & 2.36 \\
Alcaligenes & 0.37 & 0.82 & 2.22 \\
Myroides & 0.92 & 1.58 & 1.72 \\
Elizabethkingia & 0.37 & 0.51 & 1.38 \\
Prolixibacter & 0.49 & 0.66 & 1.35 \\
Deinococcus & 2.10 & 2.64 & 1.26 \\
\hline
\end{tabular}

such study especially in the field of coke wastewater treatment, where this process seems to be common (Liu et al. 2015; Lü et al. 2012; Yang et al. 2017).

The increase of Parabacteroides seems to be a natural process, because this anaerobic bacterium and its close relatives have been already identified in the biofilm system performing nitrogen and phosphorus removal (Feng et al. 2013); thus, it could be suspected that they are the natural biofilm inhabitant and the conditions in the system caused by the medium change was suitable for their multiplication. Their increase in the biofilm could be explained with their anaerobic metabolism which locates these bacteria in the bottom of the biofilm. Parabacteroides was protected against the harmful real coke wastewater influence by the upper layers of the biofilm in which aerobic nitrifiers were located.

Wastewater treatment plants are a potential source of pathogenic bacteria that can be spread not only via water and soil but they also can be aerosolized, becoming a source of airborne infections (Yang et al. 2019). NGS-based studies of pathogens present in WWTP communities as well as their presence and quantification in the effluent have already been recognized as a good solution for bacterial diseases prevention method (Lu et al. 2015). As WWTP bacterial communities are highly diverse, they can be a source not only of the common pathogens such as Bacillus (B. cereus) or Escherichia coli (Uhrbrand et al. 2017) but they can function as a reservoir of less known but comparably dangerous microorganisms. This study revealed the presence of several bacteria recognized as pathogenic but relatively less known and common.

The genus Riemerella is mainly known as a bird disease agent (mainly pigeons and ducks) (Segers et al. 1993; Rubbenstroth et al. 2013). But it was also found in wastewater treatment systems with activated sludge (Meli et al. 2016). This result supports the statement that all types of WWTPs could be the reservoirs of pathogenic bacteria.

The number of bacterial genera, Microbacterium, Planctomycetes, Gramella, Prosthecobacter, Subtercola, Sphingobacterium, and Pirellula and Leifsonia, decreased in sample 823 more than tenfold in comparison with sample 632 (Table 3).

Although Microbacterium is known to be a pathogenic bacteria, according to Chung et al. (2016), Microbacterium
Table 3 The list of bacterial genera that decreased during process performance (only genera with the relative abundance higher than $0.1 \%$ are shown)

\begin{tabular}{llll}
\hline Genus & 632 sample & 823 sample & Change (fold) \\
\hline Microbacterium & 1.23 & 0.01 & 123 \\
Planctomyces & 2.82 & 0.04 & 70.5 \\
Gramella & 0.56 & 0.01 & 56 \\
Prosthecobacter & 1.35 & 0.03 & 45 \\
Subtercola & 0.58 & 0.02 & 29 \\
Sphingobacterium & 0.74 & 0.03 & 24.66 \\
Pirellula & 0.53 & 0.023 & 23.04 \\
Leifsonia & 0.8 & 0.05 & 16 \\
Glaciibacter & 1.02 & 0.14 & 7.28 \\
Flavobacterium & 1.09 & 0.18 & 6.05 \\
Isosphaera & 0.7 & 0.12 & 5.83 \\
Hyphomicrobium & 0.54 & 0.1 & 5.4 \\
Salinibacterium & 0.62 & 0.15 & 4.13 \\
Hymenobacter & 1.74 & 0.62 & 2.8 \\
Chthoniobacter & 1.09 & 0.53 & 2.05 \\
Cytophaga & 2.48 & 1.3 & 1.9 \\
Nitrosomonas & 1.34 & 0.93 & 1.44 \\
\hline
\end{tabular}


was isolated from the textile wastewater and able to degrade polyvinyl alcohol together with the other isolated strain of Paenibacillus. Moreover, it is also described as sulfamethoxazole degrader (Bouju et al. 2012). Thus, it could be suspected that real coke wastewater caused the decrease of these bacteria due to their higher sensitivity (as potentially pathogenic bacteria), but in the first part of the experiment on the synthetic wastewater, this bacterium could be responsible for recalcitrant and other wastewater compounds removal.

The decrease of Planctomycetes as the representatives of ammonium removal bacteria seems to be justified also at this taxonomical level. High toxic load in the feeding medium was the probable reason why these bacteria number was reduced. This change probably caused the change of autotrophic nitrogen removal into heterotrophic. It is worth mentioning that Pirellula, in which the number also decrease during the experiment, belongs to marine Planctomycetes (Glöckner et al. 2003) but probably is not linked with anaerobic ammonia oxidation; however, it could be suspected that the mechanism of harmful influence of real coke wastewater in both microorganisms is similar.

Gramella, a representative of Bacteroidetes, possesses NosZ genes linked with denitrification (Jung et al. 2013), so it could be suspected that in this research Gramella was responsible for denitrification but its number decreased due to the harmful real coke wastewater influence on the nitrogen removal bacteria. The same factor caused the decrease of Subtercola which according to the patent of Vanotti et al. (2009) is one of 16 critical genera in the activated sludge performing nitrification of high ammonium concentration at low temperature; thus, it is possible that the fluctuations of ammonia nitrogen concentration and that higher than in the first part of the experiment temperature of the real wastewater were the factors causing the decrease of these bacteria number.

According to the previous research, there are some representatives of Prosthecobacter (P. algae sp. nov.) isolated from activated sludge able to nitrate reduction to nitrite (Lee et al. 2014); thus, it could be suspected that bacteria belonging to this genus could be responsible for nitrogen removal processes in wastewater treatment and real coke wastewater was also the factor causing their number decrease.

According to previous statements, Sphingobacterium is relatively ubiquitous. These bacteria have been isolated from Antarctic soil, compost, and clinical samples also with opportunistic infections (Holmes et al. 1982; Yabuuchi et al. 1983; Shivaji et al. 1992; Kim et al. 2006). Also, Leifsonia and its close relatives were isolated from the environmental samples such as sewage sludge compost (Vaz-Moreira et al. 2008), soil (Madhaiyan et al. 2010), and water (Han et al. 2013). In the case of Han et al.'s (2013) research, these bacteria caused septicemia. Decrease of these genera number could be caused by high toxic load in real coke wastewater, but still, its presence in the wastewater treatment system underlines the fact that wastewater and systems for its treatment can be a pathogen reservoir.

\section{Conclusions}

Molecular approach enables to show the change in bacterial community structure driven by many environmental factors. The feeding medium change influences the wastewater treatment efficacy; thus, it could be assumed that it also influences the bacterial community composition. This analysis revealed that bacteria usually recognized as commonly present in WWTP systems such as Nitrospira or Nitrobacter in this case were absent or below detection threshold. From the group of bacteria typically recognized as nitrogen-removing, only Nitrosomonas was above the detection threshold and its relative abundance decreased during the experiment. Instead, there is a large number of bacteria, less known in the field of nitrogen removal in wastewater treatment, which probably can lead several processes belonging to nitrogen cycle in the WWTP systems, such as the heterotrophic nitrification (Acinetobacter sp.) or denitrification (Gramella sp.). Particularly, heterotrophic nitrification and bacteria performing this process seem to be interesting topic as such microorganisms have been already found and described in coke wastewater plants as important players in nitrogen cycle. Also, the other genera such as Pseudomonas sp. or Microbacterium sp., in which its presence in WWTP systems can be surprising, may deal with a myriad of recalcitrant effectively.

This research revealed a high number of pathogenic bacteria and the other microorganisms regarded as potentially pathogenic (such as Leifsonia or Sphingobacterium). These results indicated the necessity to monitor not only the WWTP systems but also wastewater effluent for the possibility of potentially pathogenic bacteria presence for the safety reasons.

These results supports the thesis that in order to describe and understand function and changeability of complex bacterial communities (not only in biofilm) dealing with difficult types of wastewater, polyphasic approach with a wide range of molecular biology tools is needed. Paying attention to bacteria able to degrade toxic substances which can also be able to remove other compounds (such as nitrogen or phosphorus) is also relevant.

Funding information These research were supported by Polish Ministry of Science and Higher Education, grant no. N N523 562138.

Open Access This article is distributed under the terms of the Creative Commons Attribution 4.0 International License (http:// creativecommons.org/licenses/by/4.0/), which permits unrestricted use, distribution, and reproduction in any medium, provided you give appropriate credit to the original author(s) and the source, provide a link to the Creative Commons license, and indicate if changes were made. 


\section{References}

Attard E, Poly F, Commeaux C, Laurent F, Terada A, Smets BF, Recous S, Roux XL (2010) Shifts between Nitrospira- and Nitrobacter-like nitrite oxidizers underlie the response of soil potential nitrite oxidation to changes in tillage practices. Environ Microbiol 12:315-326

Boucabeille C, Bories A, Ollivier P (1994) Degradation of thiocyanate by a bacterial coculture. Biotechol Lett 16:425-430

Bouju H, Ricken B, Beffa T, Corvini PF-X, Kolvenbacha BA (2012) Isolation of bacterial strains capable of sulfamethoxazole mineralization from an acclimated membrane bioreactor. Appl Environ Microbiol 78:277-279

Cema G, Zabczynski S, Ziembinska-Buczynska A (2016) The assessment of the coke wastewater treatment efficacy in rotating biological contactor. Water Sci Technol 73:1202-1210

Chung J, Kim S, Choi K, Kim J-O (2016) Degradation of polyvinyl alcohol in textile waste water by Microbacterium barkeri KCCM 10507 and Paenibacillus amylolyticus KCCM 10508. Environ Technol 37:452-458

Ciesielski S, Kulikowska D, Kaczówka E, Kowal P (2010) Characterization of bacterial structures in two-stage moving-bed biofilm reactor (MBBR) during nitrification of the landfill leachate. J Microbiol Biotechnol 20:1140-1151

Cortez S, Teixeira P, Oliveira R, Mota M (2008) Rotating biological contactors: a review on main factors affecting performance. Rev Environ Sci Biotechnol 7:155-172

Cydzik-Kwiatkowska A, Zielińska M (2016) Bacterial communities in full-scale wastewater treatment systems. World J Microbiol Biotechnol 32:66

Cydzik-Kwiatkowska A, Zielińska M, Wojnowska-Baryła I (2012) Impact of operational parameters on bacterial community in a fullscale municipal wastewater treatment plant. Pol J Microbiol 61(1): $41-49$

Duque AF, Bessa VS, Castro PM (2014) Bacterial community dynamics in a rotating biological contactor treating 2-fluorophenol-containing wastewater. J Ind Microbiol Biotechnol 41:97-104

Felföldi T, Székely AJ, Gorál R, Barkács K, Scheirich G, András J, Rácz A, Márialigeti K (2010) Polyphasic bacterial community analysis of an aerobic activated sludge removing phenols and thiocyanate from coke plant effluent. Bioresour Technol 101:3406-3414

Feng CJ, Zhang ZJ, Wang SM, Fang F, Ye ZL, Chen SH (2013) Characterization of microbial community structure in a hybrid biofilm-activated sludge reactor for simultaneous nitrogen and phosphorus removal. J Environ Biol 34:489-499

Figuerola ELM, Erijman L (2007) Bacterial taxa abundance pattern in an industrial wastewater treatment system determined by the full rRNA cycle approach. Environ Microbiol 9:1780-1789

Glöckner FO, Kube M, Bauer M, Teeling H, Lombardot T, Ludwig W, Gade D, Beck A, Borzym K, Heitmann K, Rabus R, Schlesner H, Amann R, Reinhardt R (2003) Complete genome sequence of the marine planctomycete Pirellula sp. strain 1 Proc. Natl Acad Sci U S A 100:8298-8303

Han L, Wang X, Gue L-T, Kang Q-Y, He L, Xu J-R (2013) Septicemia caused by Leifsonia aquatica in a healthy patient after retinal reattachment surgerY. J Clin Microbiol 51:3886-3888

Holmes B, Owen RJ, Hollis DG (1982) Flavobacterium spiritivorum, a new species isolated from human clinical specimens. Int J Syst Bacteriol 32:157-165

Huang H, Feng C, Pan X, Wu H, Ren Y, Wu C, Wei C (2013) Thiocyanate oxidation by coculture from a coke wastewater treatment plant. J Biomater Nanobiotechnol 4:37-46

Jung J, Choi S, Jung H, Scow KM, Park W (2013) Primers for amplification of nitrous oxide reductase genes associated with Firmicutes and Bacteroidetes in organic-compound-rich soils. Microbiology 159:307-315
Kim K-H, Ten LN, Liu M, Im W-T, Lee S-T (2006) Sphingobacterium daejeonense sp. nov., isolated from a compost sample. Int J Syst Evol Microbiol 56:2031-2036

Klindworth A, Pruesse E, Schweer T, Peplies J, Quast C, Horn M, Glockner O (2013) Evaluation of general 16S ribosomal RNA gene PCR primers for classical and next-generation sequencing-based diversity studies. Nucleic Acids Res 41(1):e1

Kowalchuk GA, Stephen JR, De Boer W, Prosser JI, Embley TM, Woldendorp JW (1997) Analysis of ammonia-oxidizing bacteria of the $\beta$ subdivision of the class Proteobacteria in coastal sand dunes by denaturing gradient gel electrophoresis and sequencing of PCRamplified 16S ribosomal DNA fragments. Appl Environ Microbiol 63:1489-1497

Lee J, Park B, Woo SG, Lee J, Park J (2014) Prosthecobacter algae sp. nov., isolated from activated sludge using algal metabolites. Int $\mathrm{J}$ Syst Evol Microbiol 64:663-667

Liu Y, Hu T, Song Y, Chen H, Lv Y (2015) Heterotrophic nitrogen removal by Acinetobacter sp. Y1 isolated from coke plant wastewater. J Biosc Bioeng 120:549e554

Lü Y, Wang X, Liu B, Liu Y, Yang X (2012) Isolation and characterization of heterotrophic nitrifying strain W1. Chin J Chem Eng 20(5): 995-1002

Lu X, Zhang X-X, Wang Z, Huang K, Wang Y, Liang W, Tan Y, Liu B, Tang J (2015) Bacterial pathogens and community composition in advanced sewage treatment systems revealed by metagenomics analysis based on high-throughput sequencing. PLoS One 10(5): e0125549. https://doi.org/10.1371/journal.pone.0125549

Ma Q, Qu Y, Shen W, Zhang Z, Wang J, Liu Z, Li D, Li H, Zhou J (2015) Bacterial community compositions of coking wastewater treatment plants in steel industry revealed by Illumina high-throughput sequencing. Bioresour Technol 179:436-443

Madhaiyan M, Poonguzhali S, Lee JS, Senthilkumar M, Chu K, Sundaram S (2010) Leifsonia soli sp. nov., a yellow-pigmented actinobacterium isolated from teak rhizosphere soil. Int J Syst Evol Microbiol 60:1322-1327

Meli K, Kamika I, Keshri J, Momba MNB (2016) The impact of zinc oxide nanoparticles on the bacterial microbiome of activated sludge systems. Sci Rep 6:39176

Meyer F, Paarmann D, D'Souza M, Olson R, Glass EM, Kubal M, Paczian T, Rodriguez A, Stevens R, Wilke A, Wilkening J, Edwards RA (2008) The metagenomics RAST server - a public resource for the automatic phylogenetic and functional analysis of metagenomes. BMC Bioinformatics 19(9):386

Nascimento AL, Souza AJ, Andrade PAM, Andreote FD, Coscione AR, Oliveira FC, Regitano JB (2018) Sewage sludge microbial structures and relations to their sources, treatments, and chemical attributes. Front Microbiol 9:1462

Nicolaisen MH, Ramsing NB (2002) Denaturing gradient gel electrophoresis (DGGE) approaches to study the diversity of ammoniaoxidizing bacteria. J Microbiol Methods 50:189-203

Pal P, Kumar R (2014) Treatment of coke wastewater: a critical review for developing sustainable management strategies. Sep Purif Rev 43: $89-124$

Parks DH, Beiko RG (2010) Identifying biologically relevant differences between metagenomic communities. Bioinformatics 26:715-721

Rotthauwe JH, Witzel KP, Liesack W (1997) The ammonia monooxygenase structural gene amoA as a functional marker: molecular fine-scale analysis of natural ammonia-oxidizing populations. Appl Environ Microbiol 63:4704-4712

Rubbenstroth D, Ryll M, Hotzel H, Christensen H, Knobloch JK-M, Rautenschlein S, Bisgaard M (2013) Description of Riemerella columbipharyngis sp. nov., isolated from the pharynx of healthy domestic pigeons (Columba livia f. domestica), and emended description of the genus Riemerella, Riemerella anatipestifer and Riemerella columbina. Int J Syst Evol Microbiol 63:280-287 
Segers P, Mannheim W, Vancanneyt M, De Brandt K, Hinz K-H, Kersters K, Vandamme P (1993) Riemerella anatipestifer gen. nov., comb. nov., the causative agent of septicemia anserum exsudativa, and its phylogenetic affiliation within the Flavobacterium-Cytophaga rRNA homology group. Int J Syst Bacteriol 43:768-776

Shivaji S, Ray MK, Rao NS, Saisree L, Jagannadham MV, Kumar GS, Reddy GSN, Bhargava PM (1992) Sphingobacterium antarcticus sp. nov., a psychrotrophic bacterium from the soils of Schirmacher Oasis, Antarctica. Int J Syst Bacteriol 42:102-106

Uhrbrand K, Schultz AC, Koivisto AJ, Nielsen U, Madsen AM (2017) Assessment of airborne bacteria and noroviruses in air emission from a new highly-advanced hospital wastewater treatment plant. Water Res 112:110-119

Vanotti MB, Szogi AA, Ducey TF (2009) High performance nitrifying sludge for high ammonium concentration and low temperature wastewater treatment. Application WO2011002683A2 patent, (https://patents.google.com/patent/WO2011002683A2/en, 10.03. 2018)

Vanparys B, Spieck E, Heylen K, Wittebolle L, Geets J, Boon N, De Vos P (2007) The phylogeny of the genus Nitrobacter based on comparative rep-PCR, 16S rRNA and nitrite oxidoreductase gene sequence analysis. Syst Appl Microbiol 30:297-308

Vaz-Moreira I, Nobre MF, Silva Ferreira AC, Schumann P, Nunes OC, Manaia CM (2008) Humibacter albus gen. nov., sp. nov., isolated from sewage sludge compost. Int J Syst. Evol Microbiol 58:1014 1018

Wang X, Hu M, Xia Y, Wen X, Ding K (2012) Pyrosequencing analysis of bacterial diversity in 14 wastewater treatment systems in China. Appl Environ Microbiol 78:7042-7047

Wang Z, Liu L, Gue F, Zhang T (2015) Deciphering cyanide-degrading potential of bacterial community associated with the coking wastewater treatment plant with a novel draft genome. Microb Ecol 70:701-709

Wertz S, Poly F, Le Roux X, Degrange V (2008) Development and application of a PCR-denaturing gradient gel electrophoresis tool to study the diversity of Nitrobacter-like nxrA sequences in soil. FEMS Microbiol Ecol 63:261-271

Xia S, Duan L, Song Y, Li J, Piceno YM, Andersen GL, Alvarez-Cohen L, Moreno-Andrade I, Huang CL, Hermanowicz SW (2010) Bacterial community structure in geographically distributed biological wastewater treatment reactors. Environ Sci Technol 44:73917396

Yabuuchi E, Kaneko T, Yano I, Moss CW, Miyoshi N (1983) Sphingobacterium gen. nov., Sphingobacterium spiritivorum comb. nov., Sphingobacterium multivorum comb. nov., Sphingobacterium mizutae sp. nov., and Flavobacterium indologenes sp. nov. glucosenonfermenting gram-negative rods in CDC groups IIk-2 and Ilb. Int J Syst Bacteriol 33:580-598

Yang Y, Liu Y, Yang T, Lv Y (2017) Characterization of a microbial consortium capable of heterotrophic nitrifying under wide $\mathrm{C} / \mathrm{N}$ range and its potential application in phenolic and coking wastewater. Biochem Eng J 120:33-40

Yang K, Li L, Wang Y, Xue S, Han Y, Liu J (2019) Airborne bacteria in a wastewater treatment plant: emission characterization, source analysis and health risk assessment. Water Res 149:596-606

Zhang B, Xu X, Zhu L (2018) Activated sludge bacterial communities of typical wastewater treatment plants: distinct genera identification and metabolic potential differential analysis. AMB Express 8:184

Publisher's note Springer Nature remains neutral with regard to jurisdictional claims in published maps and institutional affiliations. 